\title{
Chagas disease: national survey of seroprevalence in children under five years of age conducted in 2008
}

\author{
Graciela Russomando ${ }^{1 /+}$, Blanca Cousiño² ${ }^{2}$ Zunilda Sanchez ${ }^{1}$, Laura X Franco', \\ Eva M Nara', Lilian Chena', Magaly Martínez¹, María E Galeano', Lucio Benitez ${ }^{2}$
}

1Universidad Nacional de Asunción, Instituto de Investigaciones en Ciencias de la Salud, Laboratorio de Biología Molecular, Asunción, Paraguay ${ }^{2}$ Ministerio de Salud Pública y Bienestar Social, Servicio Nacional de Erradicación del Paludismo, Asunción, Paraguay

BACKGROUND Since the early 1990s, programs to control Chagas disease in South America have focused on eradicating domiciliary Triatoma infestans, the main vector. Seroprevalence studies of the chagasic infection are included as part of the vector control programs; they are essential to assess the impact of vector control measures and to monitor the prevention of vector transmission.

OBJECTIVE To assess the interruption of domiciliary vector transmission of Chagas disease by $T$. infestans in Paraguay by evaluating the current state of transmission in rural areas.

METHODS A survey of seroprevalence of Chagas disease was carried out in a representative sample group of Paraguayans aged one to five years living in rural areas of Paraguay in 2008. Blood samples collected on filter paper from 12,776 children were tested using an enzyme-linked immunosorbent assay. Children whose serology was positive or undetermined $(\mathrm{n}=41)$ were recalled to donate a whole blood sample for retesting. Their homes were inspected for current triatomine infestation. Blood samples from their respective mothers were also collected and tested to check possible transmission of the disease by a congenital route.

FINDINGS A seroprevalence rate of $0.24 \%$ for Trypanosoma cruzi infection was detected in children under five years of age among the country's rural population. Our findings indicate that T. cruzi was transmitted to these children vertically. The total number of infected children, aged one to five years living in these departments, was estimated at 1,691 cases with an annual incidence of congenital transmission of 338 cases per year.

MAIN CONCLUSION We determined the impact of vector control in the transmission of T. cruzi, following uninterrupted vector control measures employed since 1999 in contiguous T. infestans-endemic areas of Paraguay, and this allowed us to estimate the degree of risk of congenital transmission in the country.

Key words: Chagas disease - domestic Triatoma infestans - Trypanosoma cruzi - interruption of transmission - seroprevalence

Chagas disease, a zoonosis transmitted by triatomine insect vectors, remains a major public health problem in most Latin American countries. In the 21 countries where the disease is endemic, an estimated 7.7 million persons are currently infected by the protozoan, Trypanosoma cruzi. Each year, approximately 41,200 new vector-borne cases of $T$. cruzi infection are reported, and 14,400 infants are born with congenital Chagas disease (OPS 2006). In South America, Triatoma infestans is the domestic vector responsible for the spread of the chagasic epidemic (WHO 2002). In recent years, epidemiological surveillance of T. cruzi infections has improved markedly in many endemic countries owing to blood bank screening and vector-control programs. Since the early 1990s, Chagas disease control programs in South America have focused on eradicating domiciliary $T$. infestans, the main vector of the pathogenic protozoan (WHO 2002, OPS 2006). These efforts have proven to be successful in Uruguay, Chile, Brazil, and the Oriental Region of Paraguay (comprising 98\% of the coun-

\footnotetext{
doi: 10.1590/0074-02760160407

+ Corresponding author: grusso@rieder.net.py

Received 9 September 2016
}

Accepted 9 January 2017 try's total population), all of which have been declared vector-transmission-free by the Pan American Health Organization. Following the success of these National Programs directed at domiciliary vector control and surveillance, prevalence rates in younger age groups have been regressing in many areas (Dias et al. 2002, Schofield et al. 2006, Moncayo \& Silveira 2009).

The interruption of domiciliary vector transmission is the highest level of control that can be achieved with information obtained through entomological indicators. In Paraguay, the baseline infestation rate and infection in humans was initially determined between 1982 and 1986. It was shown that $60 \%$ of the departments in the country (mainly in rural areas) had an infestation rate of $T$. infestans ranging from $11-30 \%$. In 1986, a national serological survey of T. cruzi infection reported a seroprevalence rate of 20-22\% in rural areas (Rojas de Arias et al. 1984, 1999).

From 1999-2007, Paraguay was in a technologically prominent position for its use of chemical control agents and entomological surveillance (Silveira 2001, Silveira $\&$ Sanches 2003, OPS 2004). These methods led to a significant reduction in the number of $T$. infestans-infested dwellings and the incidence/prevalence of Chagas disease in broad endemic areas (Dias et al. 2002, Schofield et al. 2006, Dias 2007). A five-year project financed in 2002 by the Canadian agency, CIDA, was launched to establish horizontal surveillance systems with the par- 
ticipation of the local community. The strategy involved local technical teams from the National Program performing active searches for vectors in infested villages from rural areas and responsibility for the training of local community leaders in the passive surveillance of vectors in households within their community. Additional local participation was achieved with the organisation of a "Chagas School Week", sponsored together with the Ministry of Education and Culture.

Seroprevalence studies of the chagasic infection are included as part of the vector control programs, and they are essential to characterise the baseline status, assess the impact of vector control measures, and monitor the prevention of vector transmission. These studies, carried out by sampling, do not necessitate any population census unless the area under study has a very small population (fewer than 100 people). To confirm the interruption of domiciliary transmission, seroprevalence studies in children aged less than five years are advised every five to 10 years (Silveira \& Sanches 2003).

The first National Serological Survey to determine a baseline status was carried out in 2001 in children aged one to five years. The seroprevalence rate measured in 14 among the 17 departments of the western region of Paraguay ranged from $0.1-1.4 \%$, with highest seroprevalence rates of $1.2 \%$ and $1.4 \%$ being recorded in Paraguarí and Cordillera departments, respectively. A total of 10,406 children were screened in the 14 selected departments; $57(0.5 \%)$ children among them were seropositive for a T. cruzi infection. Finally, for four among these $57 \mathrm{~T}$. cruzi-confirmed seropositive children, the mothers were seronegative, and one child had received a prior blood transfusion. This information was documented to update the findings that had been gathered on the extent and the risk of the transmission of Chagas disease in Paraguay in 2001 (Peñaranda-Carrillo et al. 2002, OPS 2004).

The aim of the present study was to conduct the second National Serological Survey in children of the same age group and to determine the impact of entomological control and surveillance programs that ran between 2000 and 2007. The results may indirectly provide an assessment of the degree of risk for congenital transmission through the confirmation of seropositive cases and the possible identification of areas still at risk for vector transmission.

\section{MATERIALS AND METHODS}

Sampling framework - Sampling procedures, conducted in 2008 in the rural areas of the 14 departments of the Oriental Region, followed those used for the 2007 population projection based on the data that had been gathered from the 2002 "National Census of Populations and Housing". Using the defined criterion, districts in the departments without any rural areas were excluded from the sampling.

Sample size - The results of the first National Serological Survey carried out in 2001 in children aged one to five years were used to estimate the prevalence and confidence interval width in each department. The endemic and non-endemic status of each department was primarily based on data relative to the infestation rate of T. infestans, historical entomological data, and the baseline entomological surveys performed in the last five years. In addition, data related to seropositive pregnant women identified in prenatal screenings and data from blood bank registers were taken into account.

Endemic departments and those with low endemicity - The departments of Caaguazú, Itapúa, Caazapá, Central, Ñeembucú, Canindeyú, Amambay, Misiones,

TABLE I

Number of cases sampled in departments and seroprevalence of Trypanosoma cruzi in children aged one to five years living in rural areas of the Oriental Region of Paraguay

\begin{tabular}{|c|c|c|c|c|c|}
\hline \multirow[b]{2}{*}{$\mathrm{N}^{\mathrm{o}}$} & \multirow[b]{2}{*}{ Department } & \multirow[b]{2}{*}{ Total population from $1-5$ years old* } & \multicolumn{3}{|c|}{ Sampling } \\
\hline & & & Districts $\left(n^{\circ}\right)$ & Localities $\left(n^{\circ}\right)$ & Samples $\left(\mathrm{n}^{\circ}\right)$ \\
\hline 1 & Concepción & 25,907 & 6 & 35 & 856 \\
\hline 2 & San Pedro & 46,822 & 12 & 30 & 820 \\
\hline 3 & Cordillera & 31,320 & 17 & 35 & 819 \\
\hline 4 & Guaira & 22,162 & 14 & 43 & 813 \\
\hline 5 & Caaguazu & 61,667 & 15 & 30 & 893 \\
\hline 6 & Caazapa & 20,182 & 10 & 50 & 1,183 \\
\hline 7 & Itapua & 64,437 & 16 & 30 & 904 \\
\hline 8 & Misiones & 12,931 & 10 & 70 & 1,063 \\
\hline 9 & Paraguari & 26,735 & 15 & 36 & 814 \\
\hline 10 & Alto Parana & 90,375 & 14 & 32 & 907 \\
\hline 11 & Central & 209,792 & 10 & 35 & 912 \\
\hline 12 & Ñeembucu & 8,107 & 16 & 88 & 800 \\
\hline 13 & Amambay & 15,531 & 3 & 75 & 1,157 \\
\hline \multirow[t]{2}{*}{14} & Canindeyú & 24,701 & 8 & 30 & 835 \\
\hline & & 660,669 & 166 & 619 & 12,776 \\
\hline
\end{tabular}

*: projection of the population for the year 2007 based on the census of 2002. 
and Alto Paraná were considered areas with low endemicity. Sample size was calculated with a prevalence of $0.4 \%$ and a confidence interval (CI) width of $0.7 \%$. The departments of Concepción, Cordillera, Paraguarí, San Pedro, and Guairá were considered historically endemic (infestation rates ranging from $0.4-2.8 \%$, determined in the last five years prior to the present survey). Sample size was calculated with an estimated prevalence of $1.25 \%$ and a CI width of $1.5 \%$.

Sampling - Each sample taken at random was processed in three stages. In the first stage, the localities in each department were selected at random with equal probability. In the second stage, households with children between one to five years of age were selected within each locality. In the third stage, a maximum of two children were selected from each household.

Selection of localities - To determine the number of localities to be selected in each department, the following considerations were taken into account: (1) the selection of the greatest number of localities possible (in order to achieve the widest distribution); (2) the sample size of children between one to five years of age to be selected in each department; (3) the proportion of children between one to five years of age in each department; (4) the variability of the number of households in each locality (according to the 2002 census); and (5) the $10 \%$ adjustment because of a possible non-response rate.

The population group between one to five years of age, according to the 2002 census, comprised 660,669 children in the 14 departments studied. The total number of existing localities was 4,245, of which 619 were selected for sampling (Table I).
Selection of households - The distribution of samples in each locality was carried out in proportion to the number of children between one to five years of age reported in the 2002 census, taking 10 households as the minimum number of households to be surveyed. When the number of children in 2002 equalled less than 10, we considered the total number.

Selection of children - From each household selected, we first chose one child aged one to five years, but only if he/she had been born and raised in that locality. When only one or two children from that age range were present in the household, one or both were utilised for the survey. If the number of children from that age range was greater than two, only two among them were randomly selected for the survey.

Sample collection and serological studies - Having obtained prior consent from parents or guardians of the children, we collected blood samples by digital puncture with a lancet onto filter paper and proceeded to draw up an epidemiological chart. The samples were stored in a refrigerator, and the cold chain was maintained when they were transferred. The detection of anti- $T$. cruzi immunoglobulin $\mathrm{G}(\mathrm{IgG})$ antibodies in the blood, collected on the filter paper, was carried out by enzyme-linked immunosorbent assay (ELISA) using the "IICS-Chagas" kit as a first step. This kit has been produced at the IICS since 1986. The "IICS-Chagas" kit utilises Y strain epimastigotes crude extract and goat anti-human IgG-peroxidase conjugate; it has a sensitivity $(95 \% \mathrm{CI})$ of 97.02 (93.2-99.0) and a specificity (95\% CI) of 99.24 (97.3-99.9) (Otani et al. 2009, do Brasil et al. 2016). The standardisation in the filter paper (Schleicher \& Schuell,

TABLE II

Distribution by department, gender and age of 12,776 children aged one to five years tested for Trypanosoma cruzi infection in 2008

\begin{tabular}{|c|c|c|c|c|c|c|c|c|c|}
\hline \multirow[b]{2}{*}{$\mathrm{N}^{\mathrm{o}}$} & \multirow[b]{2}{*}{ Department } & \multirow[b]{2}{*}{ Samples tested $\left(\mathrm{n}^{\circ}\right)$} & \multicolumn{2}{|c|}{ Gender } & \multicolumn{5}{|c|}{ Age (in years) } \\
\hline & & & M & $\mathrm{F}$ & 1 & 2 & 3 & 4 & 5 \\
\hline 1 & Concepción & 856 & 465 & 391 & 128 & 122 & 133 & 203 & 270 \\
\hline 2 & San Pedro & 820 & 440 & 380 & 153 & 194 & 201 & 261 & 11 \\
\hline 3 & Cordillera & 819 & 405 & 414 & 112 & 137 & 231 & 215 & 124 \\
\hline 4 & Guaira & 813 & 413 & 400 & 218 & 191 & 179 & 222 & 3 \\
\hline 5 & Caaguazu & 893 & 451 & 442 & 144 & 205 & 227 & 297 & 20 \\
\hline 6 & Caazapa & 1,183 & 659 & 524 & 209 & 242 & 287 & 323 & 122 \\
\hline 7 & Itapua & 904 & 455 & 449 & 139 & 145 & 195 & 212 & 213 \\
\hline 8 & Misiones & 1,063 & 541 & 522 & 143 & 155 & 205 & 250 & 310 \\
\hline 9 & Paraguari & 814 & 435 & 379 & 143 & 151 & 159 & 212 & 149 \\
\hline 10 & Alto Parana & 907 & 470 & 437 & 115 & 181 & 163 & 225 & 223 \\
\hline 11 & Central & 912 & 495 & 417 & 115 & 179 & 204 & 301 & 113 \\
\hline 12 & Neembucu & 800 & 430 & 370 & 107 & 141 & 173 & 234 & 145 \\
\hline 13 & Amambay & 1,157 & 608 & 549 & 183 & 226 & 216 & 216 & 316 \\
\hline \multirow[t]{2}{*}{14} & Canindeyú & 835 & 418 & 417 & 139 & 175 & 206 & 202 & 113 \\
\hline & & 12,776 & 6,685 & 6,091 & 2,048 & 2,444 & 2,779 & 3,373 & 2,132 \\
\hline
\end{tabular}




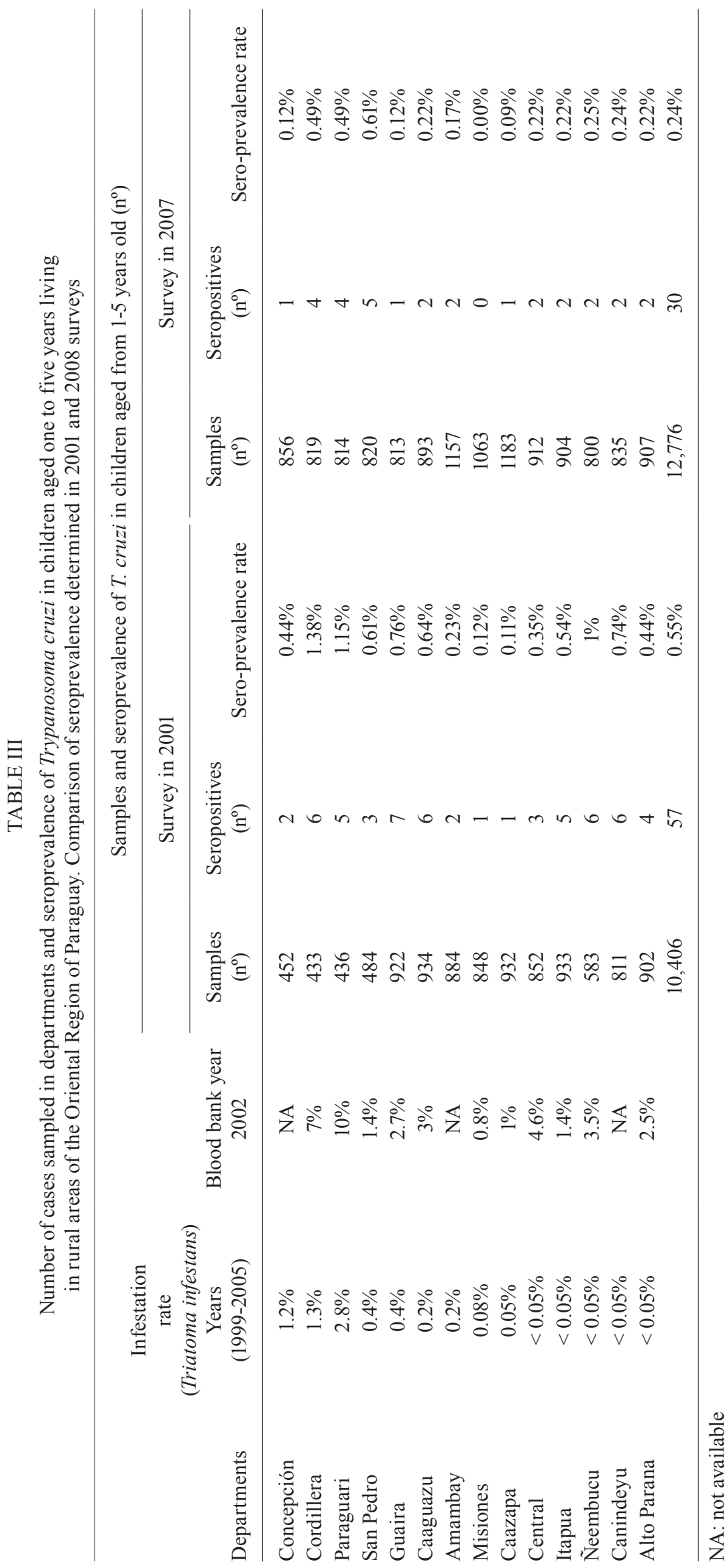


Germany) was performed in the IICS, and it has been used by our group since 1998 in children (Russomando et al. 2005). Briefly, one drop of blood is collected in a standardised circle, cut with a punch, and placed in 250 $\mu \mathrm{L}$ of the ELISA kit incubation buffer, overnight at $4^{\circ} \mathrm{C}$.

The maximum amount of time needed for processing, analysis, repetition, and confirmation was 30 days. We reconfirmed suspected positive cases with a second sample drawn by venipuncture that we tested by the conventional techniques of ELISA "IICS-Chagas" and indirect immunofluorescence test (IIF). The IIF reagents consisted of Y strain epimastigotes of T. cruzi and anti-human IgG-fluorescein conjugate. The cut off for IIF was a dilution of 1/20.

\section{RESULTS}

Samples collected on filter paper - From January to April 2007, a total of 12,776 blood samples were collected from one to five-year-old children distributed in 619 localities in 166 districts of 14 departments of the Oriental Region of Paraguay. In this sampling, $52.2 \%$ of the children were female and $47.8 \%$ male, and the number sampled per age was very representative within the selected range (Table II).

Collection of venous blood and reconfirmation of positive cases - A total of 41 positive and borderline $T$. cruzi-infected children were identified in the initial testing. Venous blood samples were subsequently drawn from both suspected children and their mothers.

The infection was confirmed in $30(0.24 \%$ seropositive) among the 12,776 children tested. All seropositive children had T. cruzi-seropositive mothers. The entomological search for triatomines in the households with cases of a child testing positive, and none having received a prior blood transfusion, proved to be negative. Mothers received counselling after they were notified that both they and their children were infected.

Seroprevalence rates in endemic and low endemic departments for children under five years following the serological survey (Table III) - With a confidence level of $95 \%$, endemic and low endemic departments showed average prevalence rates of $0.36 \%$ and $0.17 \%$, respectively. The prevalence rates are significantly lower than the results obtained in the national survey from 2001 that reported average prevalence rates of $0.84 \%$ and $0.44 \%$, respectively.

\section{DISCUSSION}

This present survey reports an estimated seroprevalence rate of $0.24 \%$ for a $T$. cruzi infection in children under five years old among the country's rural population. The fact that only $30(0.24 \%)$ cases among the 12,776 children tested were seropositive for a $T$. cruzi infection is a strong indication that the domiciliary transmission by T. infestans in the Oriental Region of Paraguay has been interrupted. This statement is supported by the following epidemiological data obtained in the present study: $100 \%$ of the children had never received a prior blood transfusion, $100 \%$ of the mothers of the infected children were also seropositive for T. cruzi (i.e., high risk for congenital transmission), and $100 \%$ of the infected children were born and raised in the same locality (under entomological surveillance since 2001). Additionally, no triatomines were detected in the dwellings at the moment of the survey.
We assume that $T$. cruzi was transmitted to these children vertically. The total number of infected children, aged one to five years living in these departments (Table II) was estimated at 1,691 cases with an annual incidence of congenital transmission of 338 cases per year. In the first National Serological Survey conducted in 2001 on the same age group, 57 (0.55\%) among 10,406 children were seropositive and four had been infected by vector transmission. It was calculated that the number of children, in this age group, infected through vertical transmission was almost twice the number of cases detected seven years earlier, i.e., 3,411 infected children in 2001. With an estimated annual incidence of 682 cases per year, it is important to point out that in the first survey the seroprevalence ranged from $0.1-1.4 \%$.

If we compare the results obtained in both surveys, we can observe in the more recent survey a near $50 \%$ reduction in: (i) the total number of infected children; (ii) the number of estimated cases of congenital transmission; and (iii) the annual incidence of vertical transmission. Given these results, we can determine the impact of vector control in the transmission of T. cruzi, following uninterrupted vector control measures applied since 1999 in contiguous T. infestans-endemic areas of Paraguay. Next, we can estimate the degree of risk of congenital transmission. Based on the technical report on entomological surveillance in the national territory that showed the presence of very few residual foci of T. infestans in historically endemic localities (OPS 2006) and the results obtained in this study, in June 2008, Paraguay received the "international certification of the interruption of domiciliary transmission of Chagas disease by T. infestans in the Oriental Region" (MSPBS 2008, OPS 2008).

\section{ACKNOWLEDGEMENTS}

To the staff of SENEPA, for their administrative and logistics support, Lic Nimia Torres, Dirección General de Estadísticas Encuestas y Censos, DGEEC/STP, for her strong technical support to the Programa Nacional de Chagas, GABRIEL network (www.gabriel-network.org), for its technical support, with Alain Johnson, for reviewing the manuscript.

\section{AUTHORS' CONTRIBUTION}

RG and CB - Study conception and design; SZ, FLX, NEM, CL, MM, GME and BL - acquisition of data/field and laboratory work; $\mathrm{RG}$ - analysis and interpretation of data and drafting of manuscript; RG and CB - critical revision.

\section{REFERENCES}

Dias JCP, Silveira AC, Schofield CJ. The impact of Chagas disease control in Latin America - A Review. Mem Inst Oswaldo Cruz. 2002; 97(5): 603-12.

Dias JCP. Southern Cone Initiative for the elimination of domestic populations of Triatoma infestans and the interruption of transfusional Chagas disease. Historical aspects, present situation, and perspectives. Mem Inst Oswaldo Cruz. 2007; 102(Suppl. 1): 11-8.

do Brasil PEAA, Castro R, de Castro L. Commercial enzyme-linked immunosorbent assay versus polymerase chain reaction for the diagnosis of chronic Chagas' disease: a systematic review and meta-analysis. Mem Inst Oswaldo Cruz. 2016; 111(1): 1-19.

Moncayo A, Silveira AC. Current epidemiological trends for Chagas disease in Latin America and future challenges in epidemiology, 
surveillance and health policy. Mem Inst Oswaldo Cruz. 2009; 104(Suppl. 1): 17-30.

MSPBS - Ministerio de Salud Pública y Bienestar Social. DGVS. Certifican la interrupción de la transmisión vectorial de la enfermedad de Chagas en el Paraguay. 2008. Available from: www. mspbs.gov.py/boletines/2008.

OPS - Organización Panamericana de la Salud. Estimación cuantitativa de la enfermedad de Chagas en las Américas. OPS/HDM/ CD/425-06. Washington (DC): OPS; 2006.

OPS - Organización Panamericana de la Salud. XVIa Reunión de la Comisión Intergubernamental de la Iniciativa Subregional Cono Sur de Eliminación de Triatoma infestans y la Interrupción de la Transmisión Transfusional de la Tripanosomiasis Americana. Assunción, June 25-27, 2008. Available from: http://www.paho. org $/$ hq/index.php?option $=$ com_docman\&task $=$ doc_view\&Itemi $\mathrm{d}=270$ \& gid $=15353$ \&lang $=$ es.

OPS - Organización Panamericana de la Salud/Taller del Cono Sur sobre enfermedad de Chagas. Conceptualización de la Vigilancia Epidemiológica. Buenos Aires, Argentina, septiembre 2003. Montevideo: OPS/DPC/CD/290/04; 2004.

Otani MM, Vinelli E, Kirchhoff LV, del Pozo A, Sands A, Vercauteren G, et al. WHO comparative evaluation of serologic assays for Chagas disease. Transfusion. 2009; 49(6): 1076-82.

Peñaranda-Carrillo R, Moreira EF, Silveira AC, Leite J, Vinhaes MC, Castro C, et al. Avaliação do impacto das ações de controle vetorial da doença de Chagas através do inquérito sorológico em Mambaí/ Buritinópolis, Goiás. Rev Soc Bras Med Trop. 2002; 35(4): 331-8.

Rojas de Arias A, Ferro E, Ferreira ME, Simancas LC. Chagas disease vector control through different intervention modalities in endemic localities of Paraguay. Bull World Health Organ. 1999; 77(4): 331-9.

Rojas de Arias A, Monzón MI, de Saldivar GV, Guillen E, Arrua N. A seroepidemiological survey of Chagas' disease in two Paraguayan villages. Bull Pan Am Health Organ. 1984; 18(2): 164-71.

Russomando G, Almirón M, Candia N, Franco L, Sánchez Z, de Guillen I. Implementation and evaluation of a locally sustainable system of prenatal diagnosis to detect cases of congenital Chagas disease in endemic areas of Paraguay. Rev Soc Bras Med Trop. 2005; 38(2): 49-54.

Schofield CJ, Jannin J, Salvatella R. The future of Chagas disease control. Trends Parasitol. 2006; 22(12): 583-8.

Silveira AC, Sanches O. Guía para muestreo en actividades de vigilancia y control vectorial de la enfermedad de Chagas. Organización Panamericana de la Salud: OPS/DPC/CD/276/03; 2003.

Silveira AC. Modelos alternativos de vigilância e controle da doença de Chagas para fases avançadas dos Programas. Grupo de Trabajo OPS en Enfermedad de Chagas. Montevideo, Uruguay, Nov. 2001. Available from: http://www.paho.org/spanish/ad/dpc/cd/consulta-2.pdf.

WHO - World Health Organization. Control of Chagas disease. Technical Reports Series. WHO. 2002; 905: 1-109. 